\title{
Mind mapping as a tool of teaching English vocabulary at transport university
}

\author{
Oksana Marunevich*, Elmira Shefieva, and Olga Bessarabova \\ Rostov State Transport University, Rostov-on-Don, Russia
}

\begin{abstract}
The core problem of teaching English as a second language at transport university is students' poor knowledge of vocabulary. Current solutions to the given problem such as providing word explanations and repetitive practices are ineffective. We strongly believe that the mindmapping technique proposed by Tony Buzan as a note-taking method is a novel, yet an extremely potent tool that aids students in enlarging their professional word stock by associating new vocabulary to their existing knowledge using colors, images, symbols, etc. As might have been expected, the findings of our study point towards the idea that the strong visual appeal of mind maps created by easy-to-use software boosted the educational process and helped students of the experimental group memorize more new words in contrast to students of the control group.
\end{abstract}

\section{Introduction}

Rostov State Transport University has around 22,000 students, who are predominantly native speakers of Russian, so learning English as a second language and especially English for railway engineers is extremely challenging for them. As reported by Marunevich \& Pernaki [1], Russian students experience numerous difficulties in their attempt to keep pace with the language requirements under the current national curriculum. Besides, they have little exposure to English in their everyday routine. The aforementioned issues greatly affect their language proficiency and desire to enlarge their word stock or master grammar, listening, and speaking skills.

The authors point out that the ability to manipulate grammatical structures does not have any sense until a person knows the meanings of the words and is able to use them to express ideas and thoughts [1]. Nunan considers the acquisition of an adequate word stock to be principal for non-native speakers. He insisted that comprehensible communication is impossible without an extensive vocabulary, which serves as a basis for learning and mastering grammar and phonetics [2]. We also strongly believe that learning new words is pivotal for broadening vocabulary and developing language skills. It is a cornerstone at transport university since a rich vocabulary knowledge provides a competitive edge in students' future careers.

Furthermore, of about 5,000 living languages, English is undoubtedly the most widely used. As a mother tongue, it ranks second only to Chinese. Indeed, fast-paced changes induced by technological development of the information age, globalization of trade and

\footnotetext{
* Corresponding author: oks.marunevich@mail.ru
} 
economic activities have turned English into an international lingua franca, a potent tool of communication worldwide. Educators, schools and universities, local authorities and even governments have made teaching English as a second language a high priority.

Generally, teaching English can be defined as a teacher's attempt to share their language knowledge, as well as speaking, listening, writing and reading skills with other individuals, i.e. students, to make the target person learn something. As stated by Clarke and Erickson, "teaching is a professional practice, where teacher engages learners in the construction of knowledge related to a particular area of study" [3]. According to Brown, teaching implies demonstrating or assisting a person in gaining an understanding of how to do something, providing instructions, tutoring in the study [4]. On the other hand, teaching English does not mean a mere transfer of vocabulary knowledge or grammar rules. It is a process of filling the students' mind with new information for successful future use. It is a process systematically organized by a teacher, educational institution, curriculum, students, and other variables to attain the pre-determined goal.

This study aims to examine the strategy of employing mind-mapping techniques to improve students' vocabulary learning and retention. It should be noted that mind-mapping is not a fresh idea. It goes back to the late 1960s, being first introduced and popularized by Tony Buzan, a famous British psychologist. The scholar drew an analogy between a mind map and a city map, considering both of them convenient for understanding and memorizing. Buzan highlighted that the center of the mind map is equal to the center of the city, whose arterial road resembles the major thought of the thinking process, while the peripheral thoroughfares are like the secondary, tertiary, etc. thoughts. He defined a mind map as "a thinking tool or a concept which illustrates how the human brain processes various thoughts and information that are related to each other" [5]. Later on, Buzan \& Buzan revised this explanation: "mind map is a strong graphical technique which targets to utilize the brain with its full capacity" [6]. Michalko interprets mind map as an alternative to linear thought and as a technique that can uncover the thoughts, which the brain has about a certain thing or idea [7]. According to Kokotovich [8], mind mapping is a note-taking technique used to write down a person's thoughts, viewpoints, and ideas. In our opinion, a mind map is a visualized mental picture of an individual's ideas and thoughts that allows seeing the big image of the subject and organize the details.

Budd explicates the given term as "an outline in which the major categories radiate from a central image and lesser categories are portrayed as branches of larger branches" [9]. Indeed, a traditional mind map has a tree-like structure that describes relationships between words, ideas, etc. around a central keyword. The parts of a mind map are as follows: a) the fundamental idea put in the heart of a mind map; b) branches that spread out from the center, i.e. the major themes of the topic; c) keywords/images that connect the theme to the main idea. They are placed at the end of the branch lines; d) secondary themes, which may be attached to this or that branch; e) nodal structure that arranges the aforementioned elements in a hierarchy.

Since the 1970s, mind-mapping has turned into a potent tool of learning, note-taking, visual thinking, brainstorming, and problem-solving in a plethora of research fields, including education, management, writing, etc. For instance, Wycoff points out that mind maps are exceptionally useful for list-making, note-taking, decision-making meetings, collective discussions, presentations, self-improvement, and developing organization skills [10]. Erdem considered mind map to be a remarkable technique that helps to form individual and collective ideas, plan and organize events, thus converting ordinary note-taking into a strategical scrutinizing [11].

Much work on the potential of mind mapping in education has been carried out. For example, Yen put this technique into his teaching practice as a visual medium to facilitate students' ability to brainstorm, arrange, and memorize new words [12]. The scholar also 
highlighted that mind mapping is a powerful tool for diminishing students' language anxiety. The study by Simonova analyzed the use of mind maps at English classes at technical universities [13]. The findings of her study validate the efficacy of mind maps as an innovative method of data visualization in contrast to linear data recording. The results of research by Putra [14] and Suseno \& Setyawan [15] offer compelling evidence for the advantages of mind mapping in improving Indonesian students' writing and grammar skills, respectively. The results reported by Al-Jarf gave an explanation of how mind mapping software assists in mastering students' pronunciation skills [16]. Munsakorn [17] and Jiang [18] emphasize that English language learners, both youngsters and adults, always find it difficult to memorize new vocabulary. However, mind maps make this process more effective and encouraging.

As stated by Suseno \& Setyawan [15], mind mapping makes English easy-to-learn and more entertaining since when concentrating on key ideas noted by their own words, symbols, or images, students can map knowledge in their personal manner which helps them understand and then recollect new words, facts, etc. Mind maps benefit students in many other respects. For instance, they assist in linking new information to previous knowledge. Next, they are a powerful tool to find an answer to difficult questions. Indeed, after writing down all the ideas, students can categorize them to get a deeper understanding of the issue. Finally, mind maps trigger students' creativity [18].

However, despite a considerable amount of literature on the use of mind maps in the educational process, not much is known about applying mind mapping to teaching English to engineering students.

\section{Materials \& Methods}

Our study lasted for the fall semester of the 2020-2021 academic year and involved two groups, which were taken randomly from seven second-year groups of the Electromechanical Department of Rostov State Transport University, Russia. Before randomly taken, all groups were given a pretest to check whether their knowledge of English vocabulary was equivalent. The two selected groups were MES-2-689 (the experimental group, $\mathrm{n}=12$ ) and MSS-2-012 (the control group, $\mathrm{n}=14$ ). As the experimental group, MES-2-689 learns new vocabulary by employing mind maps, while students of MSS-2-012 enlarge their word stock by conventional memorizing and linear note-taking.

Based on the documentation at university, the students' age ranged from 18 to 20 years old, with an average of 18.5, and there were twenty male and six female students in the cohort. For almost all of these subjects, English was the second language that they learned since their first language was Russian. Only for two students, it was their third language following Armenian and Ukrainian, respectively.

After the experiment, we asked students of the experimental group to answer the following questions:

- Was the mind-mapping technique useful for you? Why (not)?

- What are the advantages and benefits of mind mapping at English classes?

- What were the constraints of applying mind maps regularly?

This part of the study was carried out following to interview technique that is among qualitative research methods. Unlike quantitive researches, qualitative ones aimed at uncovering relations and gaining an explanation of phenomena or events rather than measuring. As stated by Patton [19], an interview is a way to get into the inner world of respondents and comprehend the issues from their viewpoint. It means individuals' own experiences are better understood from the language they speak, from the way they interpret and explain ideas and thoughts. 


\section{Results \& Discussion}

It is generally accepted that vocabularies in the human brain create semantic networks similar to maps that represent their knowledge in form of interconnected nodes. Hence, mind mapping is a powerful tool to support learning vocabulary through the visualization of related information. For instance, the key vocabulary at transport university includes such words and word combinations as transport, transport systems, transport infrastructure, train, rolling stock, traffic, cargo and passenger turnover, marshaling yard, etc. [20].

During English classes, the students of the experimental group were asked to create mind maps of new words, exploiting free easy-to-use software, downloaded from https://www.mindmeister.com (Fig. 1).

As seen from Figure 1, the given mind map has a hierarchical horizontal structure. The first and second levels of subordinate branches radiated from the dominant word combination transport systems are diverse issues related to the central topic. They cover the history of transportation, in particular, the invention of bicycle, train, and car, as well as the impact of transport on society and environment, provoking students to discuss its pros and cons. Finally, the mind map deals with materials different modes of transport are made of, their parts, electronic equipment, and machines designed to convert energy into mechanical one. So when it comes to transport systems, students will easily associate it with the aforementioned aspects.

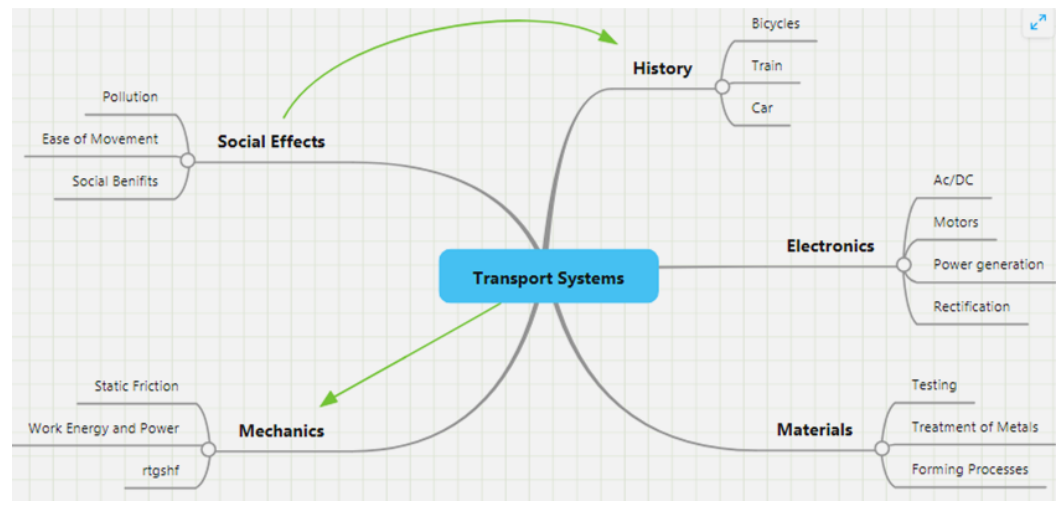

Fig. 1. Mind map "Transport systems" (created using https://www.mindmeister.com).

Upon the experiment completion, both groups were given a posttest, whose results were estimated by one-way analysis of variance (one-way ANOVA). It was found that the mean posttest value of the experimental group was equal to 76.273, while the mean posttest value of the control group did not exceed 69.514 (Table 1). The result to emerge from the given data manifests a significant difference between the two groups. It proves by the level of significance $(0.007)$ that is lower than 0.05 .

Table 1. Results of One Way ANOVA analysis.

\begin{tabular}{|l|c|c|c|c|c|}
\hline \multicolumn{1}{|c|}{ Score } & Sum of Squares & df & Mean Square & F & Significance \\
\hline $\begin{array}{l}\text { Between } \\
\text { Groups }\end{array}$ & 593.211 & 2 & 593.211 & 7.413 & 0.007 \\
\hline Within Groups & 5684.651 & 71 & 76.014 & & \\
\hline Within Groups & 6277.682 & 73 & & & \\
\hline
\end{tabular}

This result has further strengthened our conviction that mind mapping as a learning technique has a positive significant effect on enlarging engineering students' vocabulary. Our experiments corroborate previous results. For instance, the findings of our study provide 
additional support for Buzan \& Buzan [6] and Putra [14] conclusions that that mind mapping can be used purposefully for teaching vocabulary.

Data obtained during the interviews are presented below in the form of histograms.

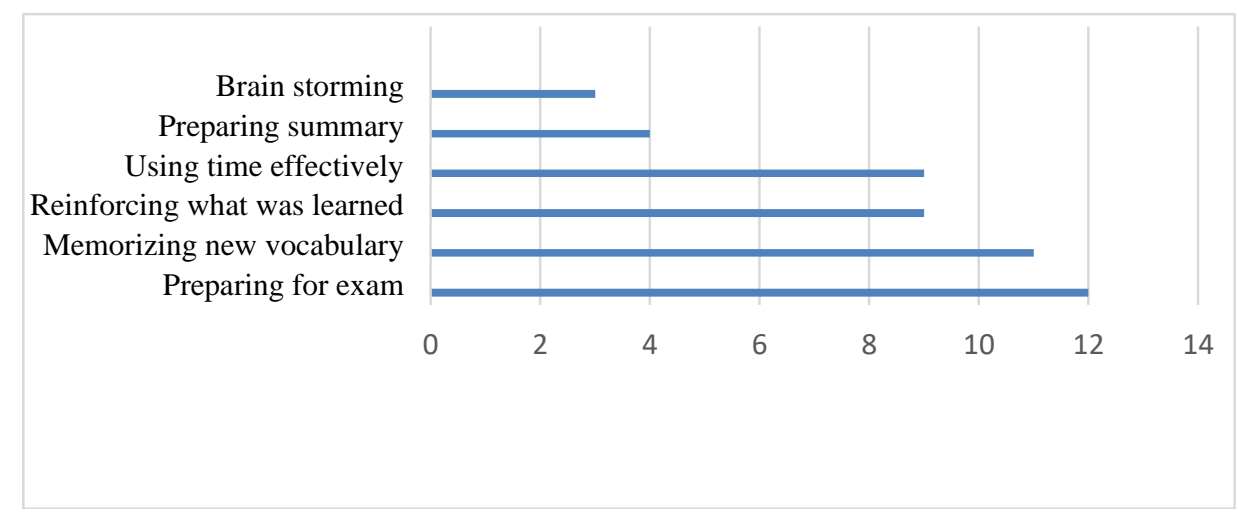

Fig 2. Answers to the question "Was mind-mapping technique useful for you? Why (not)?"

Figure 2 summarizes the students' answers given to the first question of the interview. All respondents found mind maps extremely useful not only for learning and reinforcing new vocabulary, but for brainstorming during discussion sessions, writing summaries of the texts they read, and for preparing for exams in general. The ability to make short, yet informative notes, to convert sentences and long passages into symbols or images an effective way to organize the learning process more effectively.

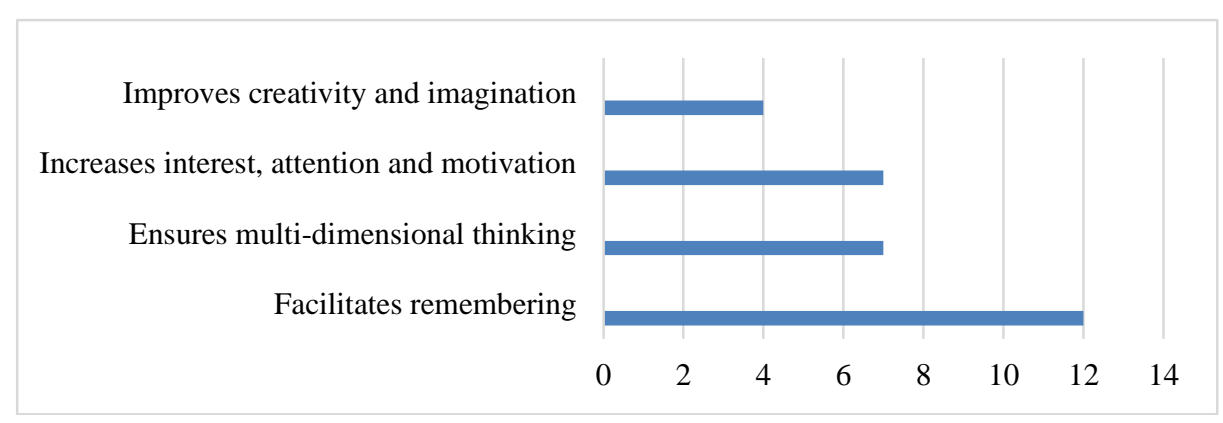

Fig 3. Answers to the question "What are the advantages and benefits of mind mapping at English classes?"

Figure 3 is interesting in several ways since the given answers can be categorized into two groups - the cognitive and the affective one. It means students examine the benefits of the mind mapping technique from diverse viewpoints. First, students are aware that mind maps are a potent learning tool that helps them remember huge arrays of data, as well as develop multidimensional thinking. Second, subjects reported on mind maps as an activity aimed at increasing interest and motivation, improving creativity and imagination. 


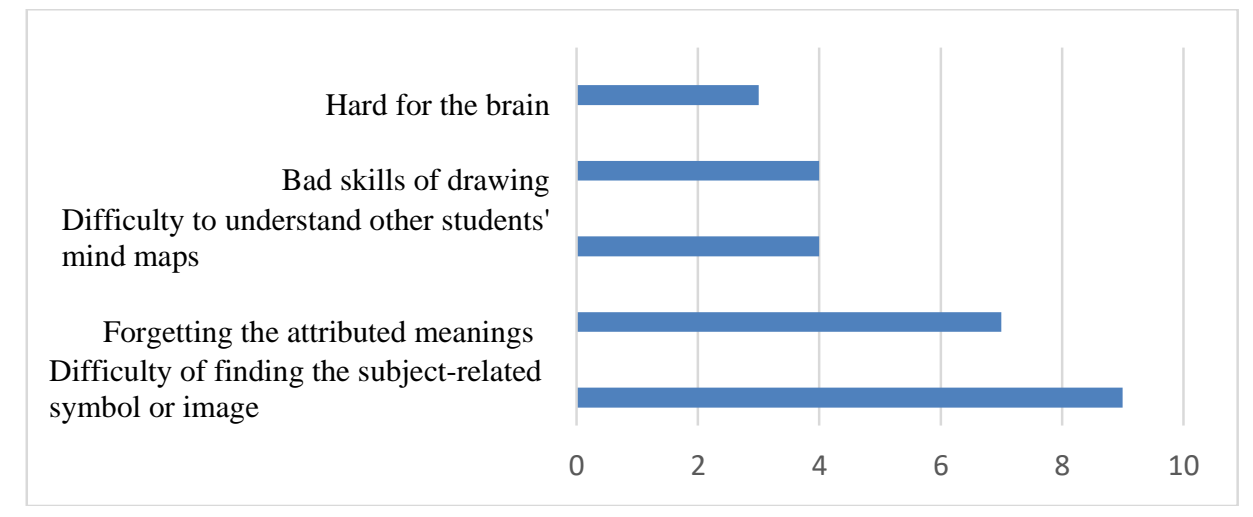

Fig 4. Answers to the question "What were the constraints of applying mind maps on a regular basis?"

From the histogram above, we can see that students had some constraints of a regular mind map using. It can be explained by the fact that creating mind maps has become the first experience for all of them. However, 11 respondents admitted that they would keep on using the mind mapping technique to learn vocabulary and improve grammar and writing skills, as well as to memorize the information provided by other teachers. Only one subject found it quite problematic to make and then read a mind map. Besides, he was always frustrated for being bad at drawing and forgetting the colored pens.

Our findings are in good agreement with Simonova [13] and Fiktorius [21]. As for positive values of mind-mapping technique, it occurred to be an excellent for brainstorming since the words and ideas are captured as they are suggested without being concerned whether they fit the given hierarchy or not. Once all ideas are captured, they are grouped, prioritized or rejected. Then, the radiating design keeps the key topic in the heart of a mind map, with major and minor subtopics close to it and to each other. Thus, this arrangement allows students to have the entire picture in focus.

Next, the flexibility of mind-mapping in contrast to traditional note-making encourages learners' creativity. A wide use of images, symbols, and colors attracts students'attention and makes learning more interesting and enjoyable.

The easy-to-understand images and symbols of a mind map save time for memorizing even the most complicated topic or notion, thus increasing students' productivity. In our opinion, mind maps are exceptionally beneficial for visual students who appreciate seeing things presented in pictures, diagrams, etc. rather than hearing them.

Finally, mind maps assist students in establishing connections between the given and new information, in transferring what they have already learnt and applying it to new situations. As stated by Al-Jarf, "compared to traditional writing instruction that depends on the textbook only, mind-mapping technique proves to be a powerful tool for improving students' ability to generate, visualize, and orginize ideas" [16].

However, it is worth noting that mind-mapping technique has certain drawbacks to be mentioned. To begin with, this technique is unfamiliar to most English language teachers and students at Russian universities. Budd [22] points out that students always find it rather difficult to draw even a plain mind map when first employing mind-mapping at class. But after getting involved into this practice on a regular basis, learners find it useful, attractive, and time-saving.

Then, since mind-mapping implies the use of images, symbols, and colors, students may feel uncomfortable. Some of them tend to forget to bring colored pencils and crayons to class, while some of them are not good at drawing. Teacher should not force learners to draw and 
color images. Mind map is student's personal vision of a topic, so it must be arrange in a way they like.

We are confident that our results may improve knowledge about mind mapping at English classes at transport university. To boost the effectiveness of learning engineering vocabulary, the teacher may ask students to draw a mind map either individually or in the group to write or tell a story since the given technique is worthwhile using to master writing and speaking skills.

\section{Conclusion}

Vocabulary is crucial for language learning since a robust word stock ameliorates speaking, writing, reading, and listening. No wonder, learning vocabulary is considered to be one of the most complicated issues in teaching English as a second language. Numerous studies proved that typical repetition is no longer an effective method for that and tried to find cutting-edge solutions for facilitating vocabulary acquisition. Our research has stressed the importance of using the mind mapping technique as it delivers remarkable benefits and advantages, especially when learning engineering terms.

Our study showed a positive significant effect of employing mind maps on the sophomores' vocabulary achievement at Rostov State Transport University. During a series of interviews, students reported on such beneficial aspects of mind mapping as assistance in preparing for exams, fostering brainstorming, developing multidimensional thinking and creativity, etc. We have obtained comprehensive results proving that engineering students adopt keywords, colors, and images, i.e. three basic components of a traditional mind map, much easier than words just written down on the blackboard.

\section{References}

1 O.V. Marunevich, E.N. Pernaki, Proceedings of XVII International conference Higher Teacher in the 21st century, 79-85 (2020)

2 D. Nunan, Teaching English to speakers of other languages (Routlage, 2015)

3 A. Clarke, G. Erickson, International handbook of self-study of teaching and teacher education on practice, (Springer, 2007)

4 H.D. Brown, Principles of language learning and teaching (Wesley Longman, 2003)

5 T. Buzan, The Ultimate Book of Mind Maps (Thorsons, 2005)

6 T. Buzan, B. Buzan, The Mind Map Book. (Edinburg, BBC Active, 2007)

7 M. Michalko, Cracking Creativity: The Secrets of Creative Genius (California Ten Speed Press, 2001)

8 V. Kokotovich, Design Studies, 29 (1), 49 (2008)

9 J.W. Budd, Journal of Economic Education, 35(1), 35 (2004)

10 J. Wycoff, Mindmapping: Your personal guide to exploring creativity and problemsolving, (Berkley Books, 1991)

11 A. Erdem, Universal Journal of Educational Research, 5(12A), 1 (2017).

12 A.C. Yen, Asian EFL Journal, 12(4), 33 (2010)

13 O.B. Simonova, Proceedings of International conference Transport: Science, Education, Manufacturing, 265 (2019)

14 P.P. Putra, International journal of humanities and Social Science, 2(21), 60 (2012) 
15 C.I. Suseno, S. Setyawan, Proceedings of the 61 TEFLIN International conference, 497 (2014)

16 R. Al-Jarf, Asian EFL Journal, 53, 4 (2011)

17 N. Munsakorn, Mediterranean Journal of Social Sciences, 3(10), 83 (2012)

18 Y.S. Jiang, Open Access Library Journal, 7 (2020)

19 Q.M. Patton, How to Use Qualitative Methods in Evaluation (Sage Pub,1987)

20 M.E. Shevchuck, O.V. Marunevich, Proceedings of the All-Russian scientific-practical conference with international participation Rational Environmental Management as the Basis of Sustainable Development, 540 (2020)

21 T. Fiktorius, The use of mind-mapping technique in the EFL classroom (University of Tanjung Pura Publications, 2013)

22 J.W. Budd, Mind maps as classroom exercise (University of Minnesota, 2003) 